\title{
Influence of the Perforated Rate on the Wave Attenuation Performance of Perforated Caisson Set on a Rubble Bed
}

\author{
Peihong ZHAO ${ }^{\text {a }}$, Dapeng $\mathrm{SUN}^{\mathrm{a}, 1}$ and Hao WU ${ }^{\mathrm{a}}$ \\ ${ }^{a}$ State Key Laboratory of Coastal and Offshore Engineering, Dalian Liaoning 116024 \\ China
}

\begin{abstract}
A Jarlan-type perforated caisson (JTPC) was an important form of structure in offshore and coastal engineering and its wave attenuation performance was greatly affected by $\mu$ (the perforated rate). In the present research, a numerical model based on VARANS equations was tested by comparing the simulation results with physical experiments and then adopted to study the effect of a larger range of $\mu$ on wave attenuation performance which included both the horizontal wave forces and the reflection coefficients. Conclusions were drawn that the total horizontal wave force and the reflection coefficient both tended to decrease and then increase with increasing $\mu$; when the reflection coefficient reached its minimum value as about $\mu=0.2$, the wave force at the seaward side of the perforated front wall tended to be equal to that at the solid rear wall; the total horizontal wave force reached its minimum value as about $\mu=0.3$.
\end{abstract}

Keywords. Reflection coefficient, perforated caisson, perforated rate, rubble bed, VARANS equations

\section{Introduction}

Since JTPC first proposed [1] by Jarlan in the last century, investigations on this form of structure using analytical or numerical models as well as physical experiments [2-6] had been continuously carried out. In engineering practice, JTPC can considerably reduce reflection coefficients and lightened the horizontal wave forces. At the meantime, it had a wide range of applications and was easy to construct, which made it an important form of structure in offshore or coastal engineering.

A series of experiments was carried out by Chen et al [7], Jiang et al [8-9] to investigate waves interaction with a JTPC. According to their experiments, the caisson was set on the flat seabed, $\mu$ (the perforated rate) was restricted to 0.2 and 0.4 . Consequently, the conclusion was drawn that the horizontal wave forces and the reflection coefficients both varied linearly with $\mu$. However, It was not examined for a JTPC set on a rubble bed. Accordingly, supplemental experiments were carried out by Xing [10]. In their experiments, the foundation was of three different heights but the $\mu$ was still restricted to 0.2 and 0.4 .

\footnotetext{
${ }^{1}$ Dapeng Sun, State Key Laboratory of Coastal and Offshore Engineering, Dalian Liaoning 116024 China; E-mail: dpsun@dlut.edu.cn.
} 
So far, it was generally believed that the perforated front wall was one of the key factors affecting the wave attenuation performance of a JTPC. But can the variation of the wave attenuation performance be described using a linear function if $\mu$ was expanded to a wider range? Most researches on a JTPC restricted $\mu$ to be a constant parameter, so this problem was not yet solved.

Accordingly, in this study, a VARANS based numerical model was tested by comparing its simulation results with physical model experiments and then adopted to investigate the effect of a wider range of $\mu$ on the attenuation performance of a JTPC set on a rubble bed.

\section{Methods}

A VARANS based numerical model which could uniformly simulate the hybrid flow [11] was adopted in following sections. The VARANS equations were defined as:

$$
\begin{aligned}
& \frac{\partial\left\langle\overline{u_{i}}\right\rangle}{\partial x_{i}}=0 \\
& \quad \frac{\partial\left\langle\bar{u}_{i}\right\rangle}{\partial t}+\frac{\left\langle\bar{u}_{j}\right\rangle}{1+c_{m}} \frac{\partial}{\partial x_{j}} \frac{\left\langle\bar{u}_{i}\right\rangle}{n} \\
& =-\frac{n}{1+c_{m}} \frac{\partial}{\partial x_{i}} \frac{\langle\bar{p}\rangle}{\rho} \\
& \quad+\frac{n}{1+c_{m}} \frac{\partial}{\partial x_{j}}\left(v+\left\langle v_{t}\right\rangle\right)\left(\frac{\partial}{\partial x_{j}} \frac{\left\langle\bar{u}_{i}\right\rangle}{n}+\frac{\partial}{\partial x_{i}} \frac{\left\langle\bar{u}_{j}\right\rangle}{n}\right)+\frac{n g_{i}}{1+c_{m}}-\frac{f_{i}}{1+c_{m}}
\end{aligned}
$$

In equation (6), $f_{i}$ alongside with the inertia term could be described by $F_{i}$, the extended Darcy-Forchheimer resistance term described as:

$$
n F_{i}=f_{i}+c_{m} \frac{\partial}{\partial t}\left\langle\bar{u}_{i}\right\rangle=a\left\langle\bar{u}_{i}\right\rangle+b|\langle\bar{u}\rangle| u_{i}+c_{m} \frac{\partial}{\partial t}\left\langle\bar{u}_{i}\right\rangle .
$$

$a$ and $b$ were empirical coefficients which need to be calibrated in advance following the method proposed by Zhao [12]. $c_{m}$ was the added mass coefficient. $\left\langle v_{t}\right\rangle$ represented the volume averaged eddy viscosity, $\langle k\rangle$ and $\langle\varepsilon\rangle$ could also be obtained following a volume averaging procedure:

$$
\begin{aligned}
\frac{\partial}{\partial t}\langle k\rangle+\left\langle\bar{u}_{j}\right\rangle \frac{\partial}{\partial x_{j}} \frac{\langle k\rangle}{n}= & 2 v_{t} n\left\langle S_{i j}\right\rangle^{f}\left\langle S_{i j}\right\rangle^{f} \\
& -\langle\varepsilon\rangle+n \frac{\partial}{\partial x_{j}}\left[\left(v+\frac{v_{t}}{n \sigma_{k}}\right) \frac{\partial}{\partial x_{j}} \frac{\langle k\rangle}{n}\right]+n \varepsilon_{\infty}
\end{aligned}
$$




$$
\begin{aligned}
\frac{\partial}{\partial t}\langle\varepsilon\rangle+\left\langle\bar{u}_{j}\right\rangle \frac{\partial}{\partial x_{j}} \frac{\langle\varepsilon\rangle}{n}= & 2 v_{t} n C_{\varepsilon 1} \frac{\langle\varepsilon\rangle}{\langle k\rangle}\left\langle S_{i j}\right\rangle^{f}\left\langle S_{i j}\right\rangle^{f} \\
& +C_{\varepsilon 2} \frac{\langle\varepsilon\rangle^{2}}{\langle k\rangle}+n \frac{\partial}{\partial x_{j}}\left[\left(v+\frac{v_{t}}{n \sigma_{k}}\right) \frac{\partial}{\partial x_{j}} \frac{\langle\varepsilon\rangle}{n}\right]+n C_{\varepsilon 2} \frac{\varepsilon_{\infty}^{2}}{k_{\infty}}
\end{aligned}
$$

where

$$
\left\langle S_{i j}\right\rangle^{f}=\frac{1}{2}\left(\frac{\partial}{\partial x_{j}} \frac{\left\langle\bar{u}_{i}\right\rangle}{n}+\frac{\partial}{\partial x_{i}} \frac{\left\langle\bar{u}_{j}\right\rangle}{n}\right) .
$$

In equation (8-9), $\sigma_{k}=1.00, \sigma_{\varepsilon}=1.30, C_{\varepsilon 1}=1.44, C_{\varepsilon 2}=1.92, k_{\infty}$ and $\varepsilon_{\infty}$ were additional sources of turbulence proposed by Nakayama and Kuwahara [13] (1999):

$$
\begin{aligned}
& \varepsilon_{\infty}=39.0 \frac{(1-n)^{\frac{5}{2}}}{n} \frac{|\langle\overline{\boldsymbol{u}}\rangle|^{3}}{d_{50}}, \\
& k_{\infty}=3.7 \frac{1-n}{\sqrt{n}}|\langle\overline{\boldsymbol{u}}\rangle|^{2} .
\end{aligned}
$$

Moreover, the VARANS equations was time-discretized using the three-step FEM. The free water surface was captured using CLEAR-VOF method.

\subsection{Validations}

As mentioned above, in those experiments carried out by Xing [10], $b_{c}$ (the waveabsorbing chamber width) of the JTPC were $0.15 \mathrm{~m}, 0.20 \mathrm{~m}$ and $0.30 \mathrm{~m}$. Several rectangular holes were cut off from the front wall leading its perforated rate $\mu$ to be 0.2 and 0.4 , respectively. $d$ (The water depth ) was $0.4 \mathrm{~m} . h_{m}$ (the heights of the rubble bed) were $0.10 \mathrm{~m}, 0.15 \mathrm{~m}$ and $0.20 \mathrm{~m}$. the berm width of the rubble bed $W$ was $0.25 \mathrm{~m}$. The core of the rubble bed and the rock fill core covering the bottom of the chamber were both the same. $n$ (the porosity) was 0.4 and $d_{50}$ (the grain diameter) was $1.1 \mathrm{~cm} . H_{\mathrm{s}}$ (the significant wave height) was $0.053 \mathrm{~m} . L_{s}$ (the significant wave lengths) were $2.35 \mathrm{~m}, 1.82$ $\mathrm{m}$ and $1.44 \mathrm{~m}$, respectively when the significant wave periods $T_{\mathrm{s}}$ were $1.38 \mathrm{~s}, 1.15 \mathrm{~s}$ and $0.99 \mathrm{~s}$. Considering all these factors, there were totally 54 cases in their experiments.

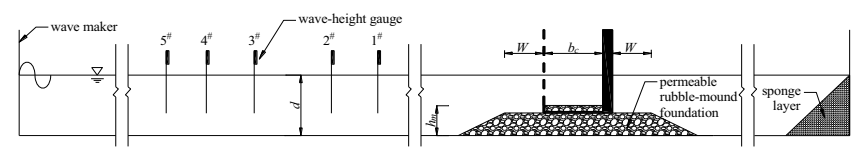

Figure 1. Setup of the wave flume and the JTPC set on the rubble bed.

Figure 1 showed a two dimensional numerical wave flume developed in this work. The flume was $15 \mathrm{~m}$ in length. A wave-maker was installed at the left boundary and the 
boundary condition was velocity inlet. The JTPC was set $7.7 \mathrm{~m}$ away from the velocity inlet.
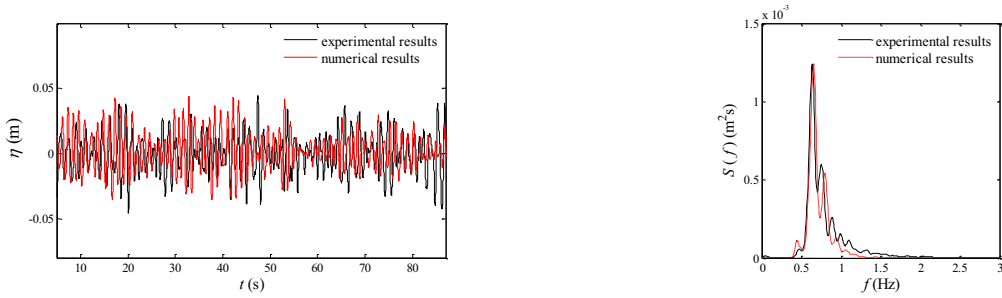

Figure 2. $1^{\#}$ time series data of wave elevation and the frequency spectrum.
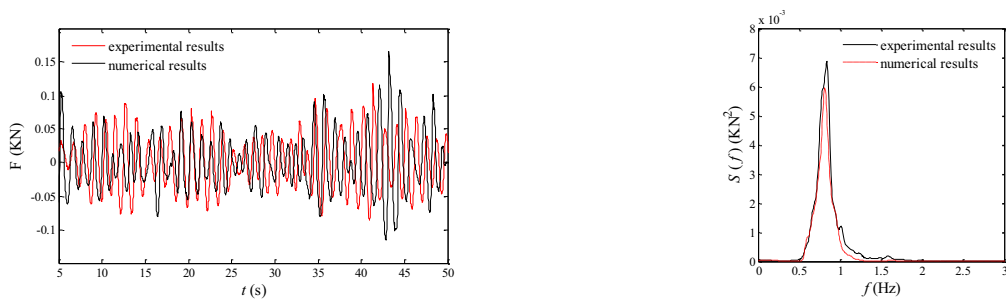

Figure 3. time series data of wave force and frequency spectrum.

The spectrum of incident waves in our numerical model and the experiments were both the modified JONSWAP spectrum [14]. The reflection coefficient of irregular waves was actually obtained by an averaging process, but for convenience, it was represented by $K r$ generally in the following research. 5 wave height gauges $\left(1^{\#}\right.$ to $5^{\#}$ plotted in figure 1) were arranged $2.8 \mathrm{~m}, 3.1 \mathrm{~m}, 3.6 \mathrm{~m}, 3.91 \mathrm{~m}$ and $4.17 \mathrm{~m}$, respectively from the front wall of the JTPC in order to accurately calculate $K r$, .

Figure 2 showed the time series data of wave elevation (wave force) alongside with the frequency spectrum detected by $1^{\#}$ gauge for $h_{m}=0.15 \mathrm{~m} ; b_{\mathrm{c}}=0.2 \mathrm{~m} ; \mu=0.4$ and $L_{s}=1.82 \mathrm{~m}$. Figure 3 showed the time series data of wave force alongside with the frequency spectrum in the same case. Two figures both showed good agreements between numerical and experimental results except for some deviation occurred in the high frequency region.

\section{Results}

The experimental cases mentioned above restricted $\mu$ to 0.2 and 0.4 . To extrapolate the effect of a wider range of $\mu$ and the variation of the attenuation performance of a JTPC set on a rubble bed, cases with different $h_{m}, \mu, b_{c}$ and $L_{\mathrm{s}}$ were tested. There were 162 cases considering the mentioned factors. The specific modeling conditions and geometric parameters were listed in table 1 .

\subsection{Effect of the Perforated rate on $K_{r}$}

The numerical and experimental $K_{r}$ was shown in figure 4 as $\mu$ varied from 0.1 to 0.7 .3 groups of cases with $b_{c}=0.15 \mathrm{~m}, 0.20 \mathrm{~m}$ and $0.30 \mathrm{~m}$ were shown separately.

Generally, as $\mu$ grew, $K_{r}$ tended to decrease and then increase. This was without exception whatever $h_{m}$ or $b_{c}$ was. $K_{r}$ reached its minimum value as about $\mu=0.2$. 
Considering the fact that reflected waves in front of the caisson contained those reflected from both the front wall and the rear wall, it indicated that as $\mu=0.2$, these two kinds of reflected waves with a phase lag overlapped and lost most energy. As $\mu<0.2$, $K_{r}$ dropped rapidly and the curve was concave; as $\mu>0.2, K_{r}$ climbed slowly and the curve was convex.

Table 1. Geometric parameters and numerical modeling conditions .

\begin{tabular}{ll}
\hline Significant wave period $T_{\mathrm{s}}(\mathrm{s})$ & $0.99,1.15,1.38$ \\
Significant wave length $L_{\mathrm{s}}(\mathrm{m})$ & $1.44,1.82,2.35$ \\
Chamber width $b_{c}(\mathrm{~m})$ & $0.15,0.20,0.30$ \\
Foundation height $h_{m}(\mathrm{~m})$ & $0.1,0.15,0.2$ \\
Perforated rate $\mu$ & $0.1,0.2,0.3,0.4,0.5,0.7$ \\
Relative foundation height $h_{m} / L_{\mathrm{s}}$ & $0.043 \sim 0.139$ \\
Relative chamber width $b_{c} / L_{\mathrm{s}}$ & $0.064 \sim 0.208$ \\
Relative water depth $d / L_{\mathrm{s}}$ & $0.17 \sim 0.278$ \\
\hline
\end{tabular}

Investigating every row of subfigure, as the $b_{\mathrm{c}}$ increased from $0.15 \mathrm{~m}$ to $0.30 \mathrm{~m}$, the curves of $K_{r} \sim \mu$ varied more dramatically.

Investigating every column of subfigure, as $h_{m}$ increased from $0.1 \mathrm{~m}$ to $0.2 \mathrm{~m}$, the curves of $K_{r} \sim \mu$ varied more gently but this phenomenon was not that sound.

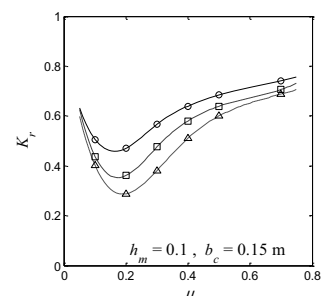

(I)

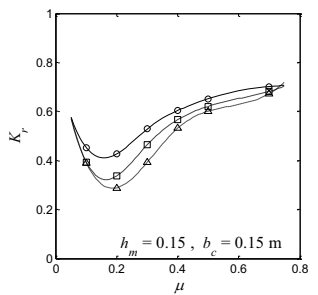

(IV)

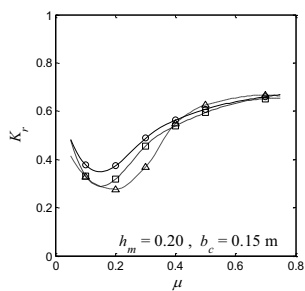

(VII)

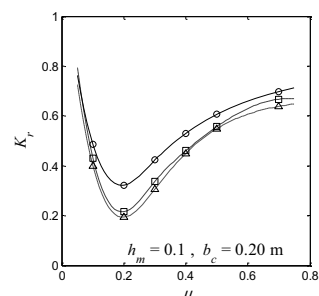

(II)

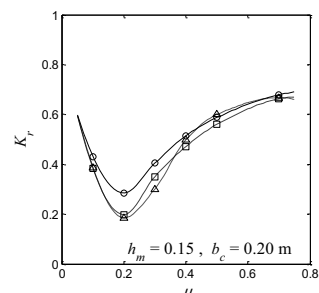

(V)

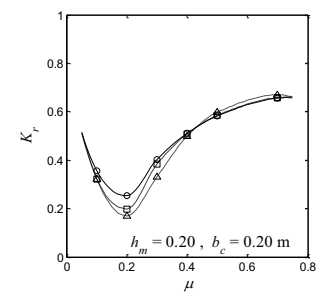

(VIII)

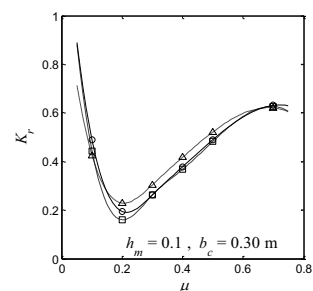

(III)

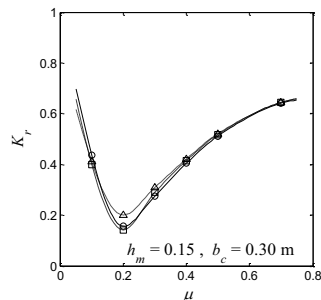

(VI)

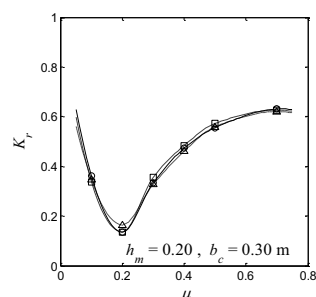

(IX)

Figure 4. $K_{r}$ for irregular waves: $\circ, L_{s}=2.35 \mathrm{~m} ; \square, L_{s}=1.82 \mathrm{~m} ; \triangle, L_{s}=1.44 \mathrm{~m}$. 


\subsection{Effect of the Perforated Rate on the Horizontal Wave Forces}

For a JTPC, $F_{h}$ (the total horizontal wave force) could be considered as the summation of 3 different components as $F_{h}=F_{h 1}-F_{h 2}+F_{h 3}$ as shown in figure 5a. Under the same conditions, as plotted in figure $5 \mathrm{~b}, F_{h 0}$ was the horizontal wave force at the traditional caisson.

Figure 6 showed the numerical and experimental horizontal wave forces components as $\mu$ varied from 0.1 to 0.7 .3 groups of cases as $b_{c}=0.15 \mathrm{~m}, 0.20 \mathrm{~m}$ and $0.30 \mathrm{~m}$ were shown separately.

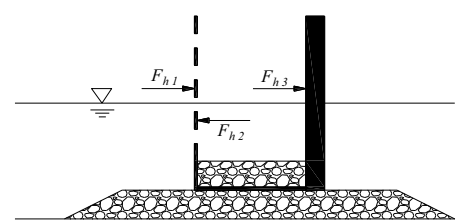

a

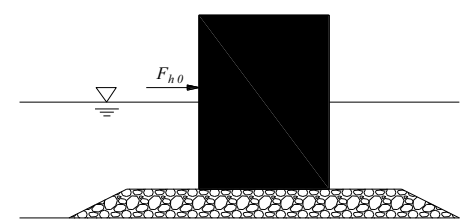

b

Figure 5. Different components of horizontal wave forces at the a. JTPC ; b. traditional caisson set on a rubble bed.

It could be found that as $\mu$ varied from 0.1 to $0.7, F_{h 1} / F_{h 0}$ decreased and $F_{h 3} / F_{h 0}$ increased monotonically. This was because that as $\mu$ grew, more wave energy passed the front wall and entered the chamber. In addition, the reduction of the force bearing area of the seaward side of the perforated front wall also led to a decrease of $F_{h 1} / F_{h 0}$. However, at the leeward side of the perforated front wall, $F_{h 2} / F_{h 0}$ first increased then decreased and the maximum values could be found at $\mu=0.2 \sim 0.3$. This was because of the coaction of the increase of the wave energy and the decrease of the force bearing area.

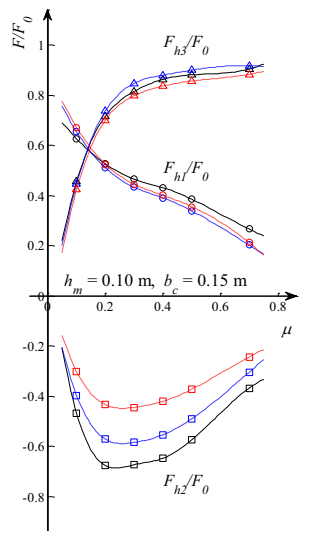

(I)

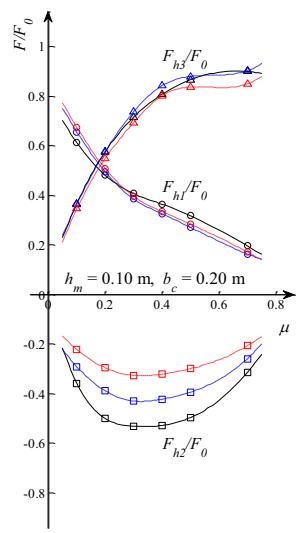

(II)

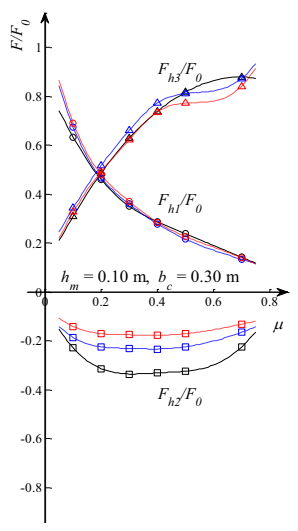

(III) 


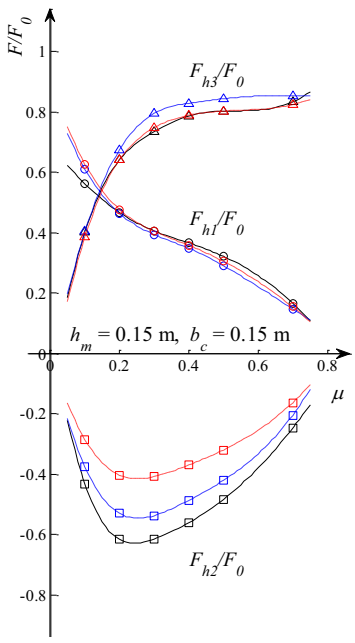

(IV)

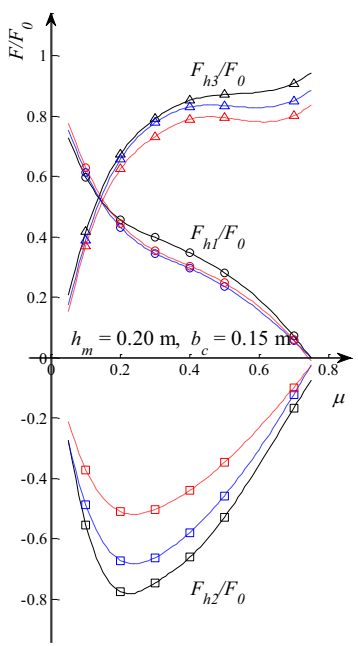

(VII)

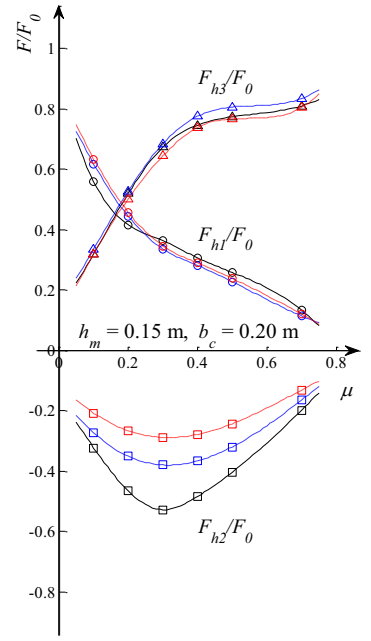

(V)

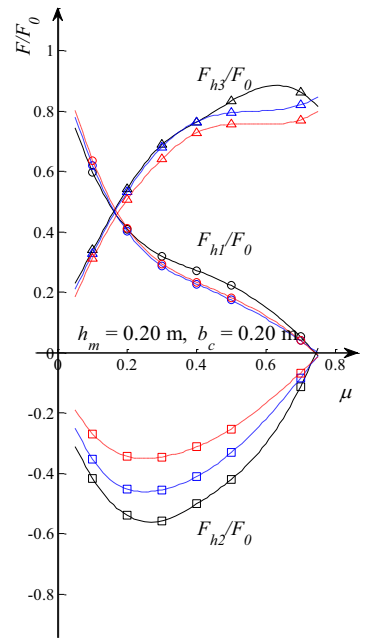

(VIII)

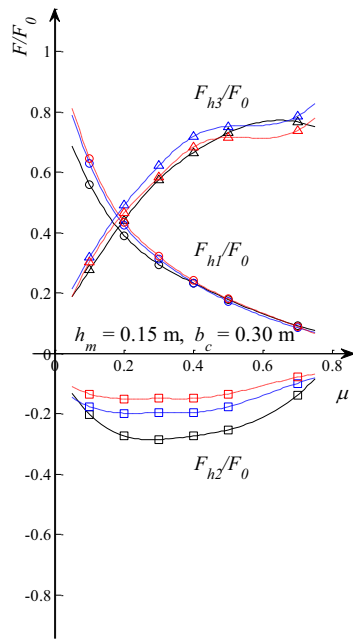

(VI)

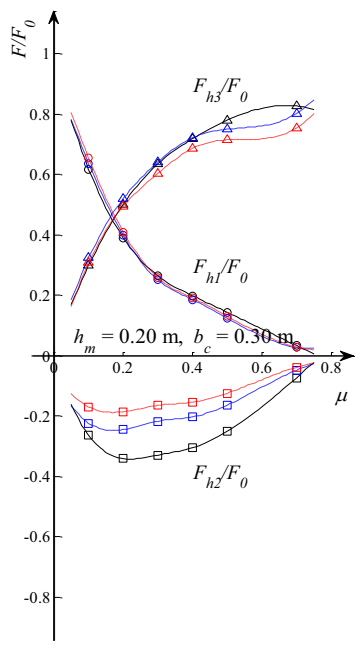

(IX)

Figure 6. Variation of three components of the horizontal wave forces with $\mu$ : black $\circ, F_{h l} / F_{h 0}$ for $L_{s}=2.35$ $\mathrm{m}$; blue $\circ, F_{h 1} / F_{h 0}$ for $L_{s}=1.82 \mathrm{~m}$; red $\circ, F_{h 1} / F_{h 0}$ for $L_{s}=1.44 \mathrm{~m}$; black $\square, F_{h 2} / F_{h 0}$ for $L_{s}=2.35 \mathrm{~m}$; blue $\square$, $F_{h 2} / F_{h 0}$ for $L_{s}=1.82 \mathrm{~m}$; red $\square, F_{h 2} / F_{h 0}$ for $L_{s}=1.44 \mathrm{~m}$; black $\triangle, F_{h 3} / F_{h 0}$ for $L_{s}=2.35 \mathrm{~m}$; blue $\triangle, F_{h 3} / F_{h 0}$ for $L_{s}$ $=1.82 \mathrm{~m}$; red $\triangle, F_{h 3} / F_{h 0}$ for $L_{s}=1.44 \mathrm{~m}$.

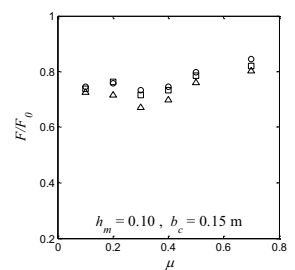

(I)

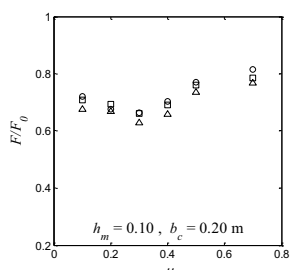

(II)

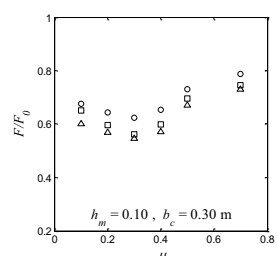

(III) 


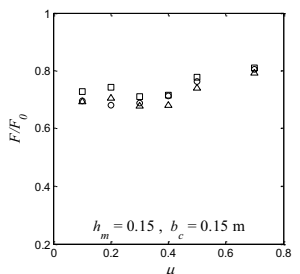

(IV)

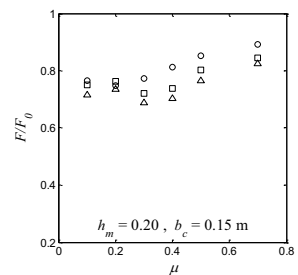

(VII)

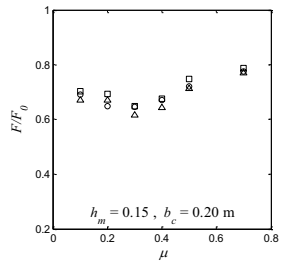

(V)

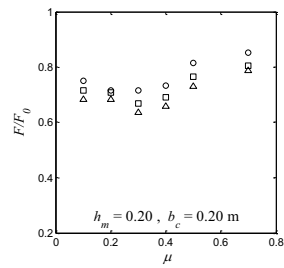

(VIII)

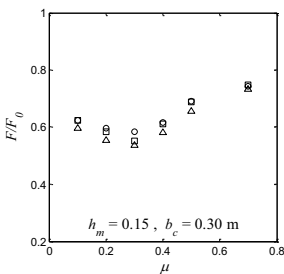

(VI)

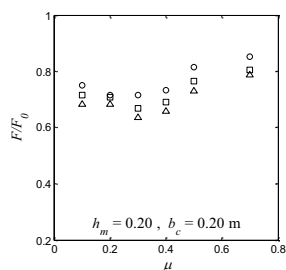

(IX)

Figure 7. Total horizontal wave force at the JTPC: $\circ, L_{\mathrm{s}}=2.35 \mathrm{~m} ; \square, L_{\mathrm{s}}=1.82 \mathrm{~m} ; \triangle, L_{\mathrm{s}}=1.44 \mathrm{~m}$.

Investigating every row and column of subfigure, it indicated that $b_{c}$ and $h_{m}$ had little influence on the curves of $F_{h 1} / F_{h 0} \sim \mu$ or $F_{h 3} / F_{h 0} \sim \mu$, but when $b_{c}$ increased, the curves of $F_{h 2} / F_{h 0} \sim \mu$ varied more gently.

By comparing figure 4 and figure 6 , it could also be found that when $K_{r}$ reached its minimum value as about $\mu=0.2$, the wave force at the seaward side of the front wall tended to be equal to that at the rear wall. This phenomenon was without exception according to the numerical results but the reason was still needed to be found and testified in the future.

Figure 7 showed the experimental and numerical total horizontal wave forces as $\mu$ varied from 0.1 to 0.7 .3 groups of cases with $b_{c}=0.15 \mathrm{~m}, 0.20 \mathrm{~m}$ and $0.30 \mathrm{~m}$ were shown separately.

In figure 7 , when $\mu$ varied from 0.1 to $0.7, F_{h} / F_{h 0}$ first decreased and then increased. Comparing to the curve of $K_{r} \sim \mu$, the curve of $F_{h} / F_{h 0} \sim \mu$ varied more gently and $F_{h} / F_{h 0}$ called for a larger $\mu$ to reach its minimum value. The total horizontal wave force reached its minimum value as about $\mu=0.3$.

\section{Conclusions}

A VARANS based numerical model was validated and carried out to study the effects of a wider range of the perforated rate on the wave attenuation performance of a JTPC set on a rubble bed. The following was a summary of our conclusions:

- The numerical model used in this research considered the permeability of the rubble bed. The simulation results were promising. Hence, this model could be used for further study on JTPC set on a rubble bed.

- The reflection coefficient tended to decrease and then increase with increasing $\mu$. The minimum value occurred as about $\mu=0.2$.

- With increasing $\mu$, horizontal wave force at the seaward side of the front wall decreased monotonically; that at the rear wall increased monotonically; that at 
the leeward side of the front wall first increased and then decreased and as about $\mu=0.2 \sim 0.3$, it reached its maximum value.

- The total horizontal wave force tended to decrease and then increase with increasing $\mu$. The minimum value occurred as about $\mu=0.3$.

- When the reflection coefficient reached its minimum value, the wave force at the seaward side of the front wall tended to be equal to that at the rear wall. This conclusion was drawn according to the numerical results without exception but it was still needed to be testified in the future.

\section{Acknowledgments}

The work described in this paper was fully supported by the NSFC-Shandong Joint Fund Project under contract U1706226.

\section{References}

[1] Jarlan GE. A perforated vertical wall breakwater. Dock Harbor Auth. 1961 Jan; 41(486): 394-398.

[2] Tanimoto K, Yoshimoto L. Theoretical and experimental study of reflection coefficient for wave dissipating caisson with a permeable front wall. Report of the Port and Harbour Research Institute 1982 Jan; 21(3): $44-77$ (in Japanese).

[3] Li RQ. Hydraulic design method of wave dissipating structure with partially perforated front wall. China Ocean Engineering. 1995 Feb; 9(1): 73-82.

[4] Chen XF, Li YCh, Sun DP, Chen RY. Experimental study of reflection coefficient and wave forces acting on perforated caisson. Acta Oceanologica Sinica. 2002 Sep; 21(3): 451-460.

[5] Chen XF, Li YCh, Wang YX, Dong GH and Bai X. Numerical simulation of wave interaction with perforated caisson breakwaters. China Ocean Engineering. 2003 Mar; 17(1): 33-43.

[6] Chen XF, Li YCh, Teng B. Numerical and simplified methods for the calculation of the total horizontal wave force on a perforated caisson with a top cover. Coastal Engineering. 2007 Jan; 54(1): 67-75.

[7] Chen XF. An experimental study of wave acting on perforated caisson. China Offshore Platform. 2001 Oct; 16(005): 1-6. (in Chinese)

[8] Jiang JJ, Li YCh, Sun DP, Ma BL. Experimental study of the vertical wave forces acting on perforated caisson by irregular waves. China Offshore Platform. 2004 Oct; 19(5): 7-14. (in Chinese)

[9] Jiang JJ, Li YCh, Sun DP, Ma BL. Experimental study of calculating for wave forces acting on perforated caisson. Port \& Waterway Engineering. 2005 Mar; 000(3): 40-47. (in Chinese)

[10] Xing T, Sun D, Wu H, Feng Y, Xia Z, Dong H . Experimental investigation on reflection coefficient of perforated caisson with rubble foundation under action of irregular wave. The Ocean Engineering. 2016 Nov; 34(6): 46-53. (in Chinese)

[11] Zhao PH, Sun DP, Wu H. Application of a VARANS based resistance-type porosity model on simulating wave interactions with perforated caisson sitting on a rubble-mound foundation. Applied Ocean Research. 2021 Jul; 112.

[12] Zhao PH, Sun DP, Wu H. Investigation on a resistance-type porosity model and the experimental Coefficients. China Ocean Engineering. 2019 Aug; 33(04): 468-476.

[13] Nakayama A, Kuwahara F. A macroscopic turbulence model for flow in a porous medium. Journal of Fluids Engineering. 1999 Jun; 121(2):427-433.

[14] Yoshimi Goda. A comparative review on the functional forms of directional wave spectrum. Coastal Engineering Journal. 1999 Mar; 41(1):1-20. 